\title{
Desenvolvimento e avaliação de um teste ELISA indireto para o diagnóstico sorológico do mormo em equídeos ${ }^{1}$
}

\author{
José Andreey A. Teles ${ }^{2}$, Ana C. Campos ${ }^{3}$, Karla P.C. da Silva ${ }^{4}$, André de S. Santos ${ }^{5}$, \\ Vânia L. de A. Santana ${ }^{6}$, Roberto S. de Castro ${ }^{7}$ e Rinaldo A. Mota ${ }^{7 *}$
}

\begin{abstract}
Teles J.A.A., Campos A.C., Silva K.P.C., Santos A.S., Santana V.L.A., Castro R.S. \& Mota R.A. 2012. [Standardization and evaluation of an indirect ELISA for the serological diagnosis of glanders in horses.] Desenvolvimento e avaliação de um teste ELISA indireto para o diagnóstico sorológico do mormo em equídeos. Pesquisa Veterinária Brasileira 32(9):838-842. Departamento de Medicina Veterinária, Universidade Federal Rural de Pernambuco, Av. Dom Manuel de Medeiros s/n, Dois Irmãos, Recife, PE 52171-900, Brazil. E-mail: rinaldo.mota@hotmail.com

Glanders is an infectious-contagious disease of acute or chronic character which principally affects horses, causing enormous losses in the productive chain of this animal. To control the disease, the Ministry of Agriculture, Husbandry and Supply instituted mandatory sanitation measures in the entire national territory which include an official diagnosis through the complement fixation (CF) test, maleinization and sacrifice of the animals that are positive. Nowadays the kits used for the diagnosis of the disease are imported, making their routine application difficult and more expensive. The objective of this study was to standardize an indirect ELISA test, using the proteic extract of Burkholderia mallei isolated from a carrier horse in the state of Pernambuco. The samples were cultivated in $10 \%$ blood agar and incubated for $48 \mathrm{~h}$ at $37^{\circ} \mathrm{C}$; later, one of the isolated colonies was characterized phenotypically and genotypically and immediately cultivated in brain heart infusion (BHI) for enrichment; then it was peaked (repicada) for the Dor-set Henley medium which was incubated at 37으 $\mathrm{Cunder} 60 \mathrm{rpm}$ for eight weeks. To standardize the test the Protein G Peroxidase Sigma Conjugate was used in the dilution of 1:90.000, with serums diluted in 1:100 and the antigen in 1:400. Sixty serums were used as negative controls, tested before the CF to determine the cutting point which was $0.042 \mathrm{~nm}$. After establishing the standardization, 300 samples were tested, of which 99\% (297) were in agreement with the results obtained in the CF. At the end, of assay presented $100 \%$ sensibility and $98.2 \%$ specificity, with predictive (preditivo) positive and negative values of $97.7 \%$ and $100 \%$ respectively. The Kappa concordance test was 0.98 and the intra and interplac repeatability were $8.8 \%$ and $10.3 \%$ respectively. From the results obtained, it is possible to affirm that the indirect ELISA test can be used as an efficient diagnosis tool. However, more essays must be carried out to consolidate the reliability of this test.
\end{abstract}

INDEX TERMS: Glanders, Burkholderia mallei, serology, ELISA, diagnosis.

\footnotetext{
${ }^{1}$ Recebido em 12 de abril de 2012.

Aceito para publicação em 4 de maio de 2012.

${ }^{2}$ Programa de Pós-Graduação em Biociência Animal (PPGBA), Universidade Federal Rural de Pernambuco (UFRPE), Dois Irmãos, Recife, PE 52171-900, Brasil. E-mail: andreey_teles@yahoo.com.br

${ }^{3}$ Programa de Pós-Graduação em Ciência Veterinária (PPGCV), UFRPE, Dois Irmãos, Recife, PE. E-mail: anabutron@gmail.com

${ }^{4}$ Depto Medicina Veterinária, Universidade Federal de Alagoas, Fazenda São Luiz s/n, Viçosa, AL 57700-000, Brasil. E-mail: karla.ufal@gmail.com
}

\footnotetext{
${ }^{5}$ Programa de Pós-Graduação em Ciência Animal Tropical (PPGCAT), Universidade Federal Rural de Pernambuco, Dois Irmãos, Recife, PE. E-mail: andresouza_santos@hotmail.com

${ }^{6}$ Laboratório Nacional Agropecuário (Lanagro), Ministério da Agricultura, Pecuária e Abastecimento (MAPA), Rua Dom Manuel de Medeiros s/n, Dois Irmãos, Recife, PE 52171-120. E-mail: vania.lucia@agricultura.gov.br.

${ }^{7}$ Departamento de Medicina Veterinária, UFRPE, Rua Dom Manuel de Medeiros s/n, Dois Irmãos, Recife, PE 52171-120. *Autor para correspondência: rinaldo.mota@hotmail.com.
} 
RESUMO.- 0 mormo é uma enfermidade infecto-contagiosa de caráter agudo ou crônico que acomete principalmente os equídeos, causando enormes prejuízos na cadeia produtiva do cavalo. Para controlar a enfermidade o Ministério da Agricultura, Pecuária e Abastecimento (MAPA) instituiu medidas sanitárias obrigatórias em todo território nacional que incluem o diagnóstico oficial pela fixação do complemento (FC), maleinização e sacrifício dos animais positivos. Os kits atuais utilizados no diagnóstico da doença são importados, dificultando e encarecendo sua aplicação na rotina. Objetivou-se com este estudo padronizar um teste de ELISA indireto utilizando o extrato protéico de Burkholderia mallei isolada a partir de equídeo portador no estado de Pernambuco. As amostras foram cultivadas em ágar sangue $10 \%$, incubada por $48 \mathrm{~h}$ a $37^{\circ} \mathrm{C}$; posteriormente caracterizou-se fenotípica e genotipicamente uma das colônias isoladas, e em seguida a cultivou em BHI para enriquecimento; logo após, esta foi repicada para o meio Dor-set Henley o qual foi incubado a $37^{\circ} \mathrm{C}$ sob $60 \mathrm{rpm}$ por oito semanas. Para padronização do teste utilizou-se o Conjugado Proteína G Peroxidase Sigma na diluição de 1:90.000, com soros diluídos em 1:100 e o antígeno em 1:400. Utilizou-se 60 soros como controle negativo testados frente à $\mathrm{FC}$ para determinação do ponto de corte o qual ficou em 0,042nm. Feitas as padronizações, foram testadas 300 amostras, onde $99 \%$ (297) foram concordantes com os resultados obtidos na FC. Ao final, o ensaio apresentou $100 \%$ de sensibilidade e $98,2 \%$ de especificidade com valores preditivo positivo e negativo de $97,7 \%$ e $100 \%$, respectivamente. 0 teste de concordância kappa foi 0,98 e a repetibilidade intra e interplaca ficaram em 8,8 e 10,3\%, respectivamente. Diante dos resultados obtidos durante os ensaios, conclui-se que o teste de ELISA indireto pode ser utilizado como uma ferramenta de diagnóstico eficiente. Entretanto, mais ensaios devem ser realizados visando consolidar a confiabilidade do referido teste.

TERMOS DE INDEXAÇÃO: Mormo, Burkholderia mallei, sorologia, ELISA, diagnóstico.

\section{INTRODUÇÃO}

0 mormo é uma doença bacteriana causada por Burkholderia mallei, sendo considerada uma das mais antigas doenças que acometem os equídeos. A bactéria causa lesões primárias na porta de entrada e na cadeia linfática adjacente (Mota 2006). 0 diagnóstico do mormo pode ser realizado por meio da associação dos aspectos clínico-epidemiológicos e anátomo-histopatológicos. Entretanto, a identificação microbiológica, inoculação em animais de laboratório, reação imunoalérgica (maleinização), testes sorológicos como fixação do complemento (FC), ensaio imuno-enzimático (ELISA), contra imunoeletroforese, hemaglutinação indireta, reação de imunofluorescência indireta (RIFI) e o teste de rosa bengala são exames complementares que auxiliam no fechamento do diagnóstico (Naureen et al. 2007). A doença ressurgiu no Brasil após várias décadas sem relatos oficiais (Mota et al. 2000). Para o diagnóstico oficial e controle do mormo no país, o Ministério da Agricultura, Pecuária e Abastecimento (MAPA) aprovou a Instrução Normativa no
24 em abril de 2004, a qual preconiza a FC e o teste da maleína como exames complementares para a identificação de animais infectados (Brasil 2004).

Embora a FC tenha uma sensibilidade de aproximadamente $90 \%$ a $95 \%$, as reações falso-negativas são ocasionalmente observadas no soro de animais jovens, gestantes e idosos e reações falso-positivas também ocorrem em aproximadamente $1 \%$ dos soros testados onde atribui-se ao uso de antígeno composto por células inteiras (Cravitz \& Miller 1950, OIE 2008a). Além disso, existem entraves quanto a padronização insuficiente do antígeno, o que pode comprometer a qualidade da reação, resultando em limitações no que diz respeito à especificidade e sensibilidade da técnica. Alguns pesquisadores ainda questionam a eficácia e aplicabilidade do referido ensaio (Jana et al. 1982, Verma et al. 1990, Neubauer et al. 2005, Naureen et al. 2007).

0 teste de ELISA indireto é bastante utilizado com finalidade de identificar, inclusive quantificar anticorpos em amostras de soro, recebendo destaque especial quando se trata de estudos soroepidemiológicos (Madruga et al. 2001). Trata-se de um tipo de ensaio que mede a interação entre o antígeno e o anticorpo, não dependendo de um segundo fenômeno como precipitação, aglutinação ou fixação do complemento (Tizard 2002).

Considerando a necessidade de ampliar as possibilidades de diagnóstico do mormo no Brasil, realizou-se com esta pesquisa com o objetivo de desenvolver e avaliar um ensaio imunoenzimático (ELISA indireto) para o diagnóstico do mormo em equídeos.

\section{MATERIAL E MÉTODOS}

Obtenção da amostra de Burkholderia mallei. As amostras de B. mallei utilizadas no ensaio imunoenzimático foram obtidas por meio da punção aspirativa do conteúdo purulento de nódulos cutâneos de três equídeos com diagnóstico clínico de mormo no estado de Pernambuco. Para o isolamento da bactéria, as amostras biológicas foram cultivadas em ágar enriquecido com sangue de ovino a $10 \%$. Posteriormente, as placas foram incubadas em estufa bacteriológica a $37^{\circ} \mathrm{C}$ por $48 \mathrm{~h}$ (OIE 2008a). As colônias que apresentaram características morfológicas semelhantes a B. mallei foram coradas pelo método de Gram e submetidas às provas bioquímicas e moleculares de identificação (Burtnick et al. 2002, Mota et al. 2005).

Caracterização fenotípica e genotípica de Burkholderia mallei. As colônias isoladas foram submetidas a testes de identificação bioquímica de oxidase, catalase, Voges Proskauer (V.P.), Vermelho de Metila (V.M.), produção de $\mathrm{H}_{2} \mathrm{~S}$ (gás sulfídrico), motilidade, indol, hidrólise da arginina, gás de D-glucose, liquefação da gelatina, urease, fermentação de carboidratos (glicose, maltose, galactose, lactose, frutose, manose, sacarose e manitol) de acordo com Mota et al. (2005). Após a caracterização fenotípica, as amostras foram submetidas à técnica de ribotipagem-PCR e RAPD-PCR utilizando-se o primer 5'-TGC CGA GCT G-3' (Leelayuwat et al. 2000).

Produção e extração da PPD-maleína. Para a produção do derivado protéico purificado (PPD-maleína), as amostras foram ressuspendidas em solução salina $(0,85 \%)$ e inoculadas em caldo Dorset Henley. Posteriormente, o meio foi incubado a $37^{\circ} \mathrm{C}$ sob agitação durante oito semanas. Após o período incubação, realizou-se a esterilização em banho-maria a $100^{\circ} \mathrm{C}$ por três horas e em seguida a filtração em membrana $0,22 \mu \mathrm{m}$ para remover as células bacterianas e substâncias indesejadas. 
Adicionou-se ao filtrado o ácido tricloroacético para precipitação das proteínas, permanecendo em repouso por 24 horas em temperatura ambiente. 0 sobrenadante da mistura foi decantado e descartado e o precipitado foi centrifugado por 15 minutos a $2.500 \mathrm{~g}$. 0 precipitado foi lavado quatro vezes em solução de $\mathrm{NaCl}$ a $5 \%(\mathrm{pH} \mathrm{3,0)}$. Em seguida o precipitado foi dissolvido com um mínimo de solvente alcalino, resultando em um $\mathrm{pH}$ 6,7. 0 produto final foi um fluído castanho escuro, o que caracteriza a maleína concentrada (Silva 2010).

A maleína concentrada foi centrifugada e o sobrenadante diluído em igual quantidade de solução tampão de glicose. A PPD-maleína de concentração 1,69mg/mL (dosado no Qubit ${ }^{\circledR}$ Fluorometer Invitrogen) foi então colocada em ampolas esterilizadas, rotuladas e refrigeradas (Verma et al. 1994, OIE 2008b).

Sensibilização dos animais. Para obtenção de soros controle positivo, cinco éguas foram sensibilizados por via sub-cutânea (SC) com $1 \mathrm{~mL}$ do antígeno inativado na concentração de $5 \mathrm{mg} / \mathrm{mL}$ e tiveram seu sangue coletado nos momentos zero (dia da inoculação), com 15 e 60 dias após a inoculação.

Padronização do ELISA. O ELISA-i foi padronizado de forma a se obter as melhores condições de diferenciação entre soros positivos e negativos e maior rendimento dos reagentes. 0 antígeno utilizado foi a maleína diluída seriadamente $(1 / 100,1 / 200$, $1 / 400$ e 1/800) e titulada frente às diluições $1 / 50,1 / 100$ e 1/200 dos soros. Como controles foram utilizados um pool de cinco soros negativos e de cinco soros positivos definidos através do teste de fixação do complemento. 0 conjugado de proteína-G peroxidase (Sigma-Aldrich, USA) foi titulado frente ao antígeno e aos soros nas diluições 1/80000,1/90000 e 1/100000.

0 teste foi realizado em placas de poliestireno de 96 poços com alta capacidade de adsorção (Greiner Bio-one). As placas foram sensibilizadas com o antígeno (PPD-maleína) e incubadas em câmara úmida durante duas horas a $37^{\circ} \mathrm{C}$. Foram realizadas três lavagens com PBS contendo 0,1\% tween 20 (v/v) (PBS-T) e as reações foram bloqueadas pela adição de solução salina tamponada com fosfato (PBS) contendo leite em pó desnatado (LPD) a $4 \%(\mathrm{p} / \mathrm{v})$ seguida de incubação por 1 hora a $37^{\circ} \mathrm{C}$ em câmara úmida. Após três lavagens com PBS-T, $100 \mathrm{~mL}$ das amostras de soros diluídas em PBS contendo LPD a $2 \%(\mathrm{p} / \mathrm{v})$ e $10 \mathrm{mM}$ de ácido etileno diamino tetracético (EDTA) (p/v) foram distribuídas em cada poço e as placas foram incubadas em câmara úmida por 1 hora a $37^{\circ} \mathrm{C}$. Após nova lavagem com solução salina tamponada com fosfato contendo Tween 20 (PBS-T), 100mL do conjugado de proteína G-peroxidase diluído foram distribuídos por poço e as placas foram incubadas por mais uma hora e posteriormente lavadas cinco vezes com PBS-T. Em seguida, $100 \mathrm{~mL}$ de solução tampão citrato-fosfato $0,1 \mathrm{M}, \mathrm{pH} 5,0$ contendo $0,1 \mathrm{mg} / \mathrm{mL}$ de $3,3^{\prime}, 5,5^{\prime}$ - tetramethylbenzidine (TMB) e $0,02 \%$ de peróxido de hidrogênio $(\mathrm{v} / \mathrm{v})$ foram adicionados à reação. Após 15 minutos, a reação foi bloqueada com $100 \mathrm{~mL}$ de ácido sulfúrico $\left(\mathrm{H}_{2} \mathrm{SO}_{4}\right) 2 \mathrm{~N}$. A leitura da densidade óptica (DO) foi realizada em leitor de microplacas com filtro ajustado em $450 \mathrm{~nm}$.

A repetibilidade do teste foi avaliada pelo cálculo do coeficiente de variação entre cinco repetições numa mesma placa (intraplaca) e entre cinco placas (interplacas), utilizando cinco soros negativos e cinco positivos, conforme recomendações da OIE (2010).

Para estimativa preliminar do ponto de corte foi realizada uma análise do desvio padrão das médias de 60 soros classificados como negativos no teste de fixação do complemento, empregando o teste $t$ de Student (Frey et al. 1998) com intervalo de confiança de $95 \%$.

Após a padronização das concentrações dos antígenos, soro e conjugado, o ELISA foi avaliado considerando-se seus valores in- trínsecos (sensibilidade e especificidade), bem como o indicador de concordância ajustado (Kappa $=k$ ) (Pereira 1995), com base no teste de 300 amostras de soros equinos classificadas previamente como positivas (129 amostras) e negativas (171 amostras) na fixação do complemento (FC), obtidas em dois laboratórios de diagnóstico credenciados pelo Ministério da Agricultura, Pecuária e Abastecimento (MAPA) para diagnóstico do mormo.

\section{RESULTADOS}

Características fenotípicas e genotípicas. A interpretação dos testes fenotípicos demonstrou que o agente comportou-se como oxidase (+), catalase (+), Voges Proskauer $(-)$, Vermelho de Metila $(-)$, produção de $\mathrm{H}_{2} \mathrm{~S}(-)$, motilidade $(-)$, indol $(-)$, hidrólise da arginina $(+)$, gás de D-glucose $(+)$, liquefação da gelatina $(-)$, urease $(-)$, glicose $(+)$, maltose $(-)$, galactose $(+)$, lactose $(+)$, frutose $(+)$, manose $(+)$, sacarose $(-)$ e manitol ( + ). Genotipicamente, a cepa selecionada para o ELISA apresentou padrão de amplificação de $1000 \mathrm{pb}$ da região espaçadora intergênica 16S-23S rRNA.

Padronização do ELISA. Após a realização de ensaios confrontando as diversas diluições possíveis tanto do antígeno quanto dos soros e do conjugado, verificou-se que as melhores diluições foram $1 / 400$ do antígeno, com os soros diluídos em 1/100 e o conjugado de proteína-G peroxidase na diluição de $1 / 90000$. Com isso, obteve-se uma intensa diferenciação entre as amostras positivas e negativas com razão positivo/negativo $(\mathrm{P} / \mathrm{N})$ de 47 . A razão $\mathrm{P} / \mathrm{N}$ foi calculada a partir da divisão da média do valor das amostras positivas pela média das amostras negativas.

Quanto à dosagem protéica da maleína concentrada, o valor observado foi de $1,69 \mathrm{mg} / \mathrm{mL}$ e a mesma após ter sido distribuída nos poços das microplacas apresentou concentração de $0,0004 \mathrm{mg} / \mu \mathrm{L}$.

0 ponto de corte estimado a partir do teste de 60 soros classificados como negativos na fixação do complemento (FC) foi de $0,042 \mathrm{~nm}$. O ELISA demonstrou boa repetibilidade com coeficiente de variação (CV) intraplaca de 8,8\% e interplacas de $10,3 \%$.

Os resultados dos soros testados no ELISA-i estão apresentados no Quadro 1, onde se observou sensibilidade de $100 \%$ e especificidade de $98,2 \%$ com ótima concordância ( $k=0,98$ - concordância ótima) com a técnica de FC. Com relação aos valores preditivo positivo e negativo, estes foram $97,7 \%$ e $100 \%$ respectivamente.

Quanto à leitura realizada nos soros dos cinco animais obtidos na segunda coleta, observou-se um aumento dos anticorpos em todos os animais quando comparado com a primeira, seguido de um decréscimo aos 60 dias (terceira leitura) da inoculação da bactéria inativada. 0 animal número 02 apresentou uma resposta imune diferente dos de-

Quadro 1. Resultado dos testes de 300 amostras séricas de equinos submetidas aos testes de fixação do complemento e ELISA-i para pesquisa de anticorpos contra o mormo

\begin{tabular}{ccccc}
\hline \multirow{2}{*}{ Teste } & & \multicolumn{2}{c}{ Fixação do Complemento } & \multirow{2}{*}{ Total } \\
\cline { 3 - 4 } & & Positivo & Negativo & \\
\hline \multirow{2}{*}{ ELISA } & Positivo & 129 & 3 & 132 \\
& Negativo & 0 & 168 & 168 \\
Total & & 129 & 171 & 300
\end{tabular}


mais nos três momentos. Este animal apresentou-se ainda como negativo frente ao teste de FC, porém ao ser analisado no ELISA-i o mesmo apresentou resultado positivo.

Os valores das densidades ópticas (DO) dos cinco soros de equinos submetidos à inoculação da bactéria inativada estão representados na Figura 1.

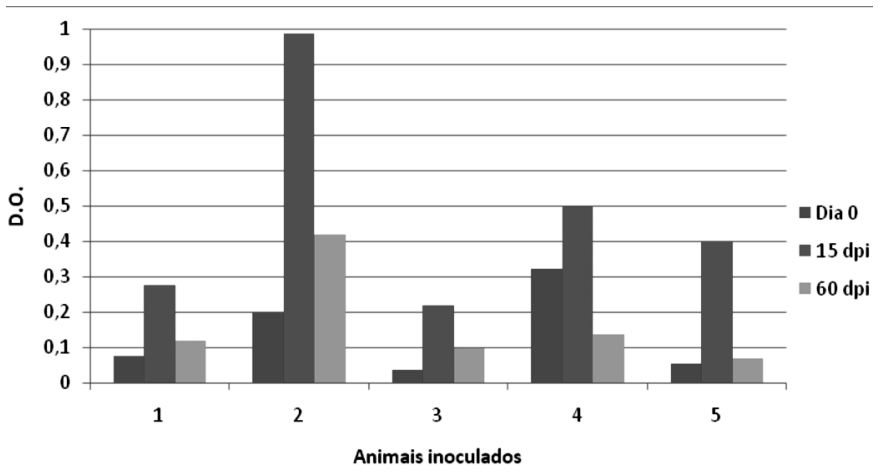

Fig.1. Resposta imunológica de equinos sensibilizados com Burkholderia mallei inativada, avaliada no teste ELISA-i, nos dias zero, 15 e 60 pós-inoculação da bactéria.

\section{DISCUSSÃO}

0 resultado obtido na análise fenotípica permitiu identificar os isolados como Burkholderia mallei, pois as colônias apresentaram características bioquímicas idênticas às observadas anteriormente por Yabuuchi et al. (1992), Al-Ani et al. (1998), Mota et al. (2005), Silva et al. (2008, 2009). Os achados genotípicos também foram compatíveis com os achados descritos por Silva et al. (2009).

Nesse estudo, a concentração protéica da PPD-maleína utilizada para sensibilizar as placas do ELISA foi de 1,69mg/ $\mathrm{mL}$, mostrando-se suficiente para uso no teste sorológico. Valor semelhante também foi observado por Santurio et al. (2006) que padronizaram um ELISA indireto (ELISA-i) para o diagnóstico da pitiose equina e utilizaram $1 \mathrm{mg} / \mathrm{mL}$, contudo, Dantas (2004) ao padronizar um ELISA indireto para Maedi-Visna utilizou concentração de $0,5 \mathrm{mg} / \mathrm{mL}$ e conseguiu obter resultados satisfatórios em sua pesquisa.

Os valores do coeficiente de variação (CV) tanto intra quanto interplaca apresentaram compatibilidade com as informações da OIE (2006) que preconiza que um teste com boa repetibilidade deve apresentar $\mathrm{CV}$ com valores abaixo de $20 \%$, o que é necessário para ser padronizado.

Os valores de sensibilidade e especificidade encontrados nesse estudo foram de $100 \%$ e $98,2 \%$, respectivamente, caracterizando o teste de ELISA-i como sendo um ensaio que não apresenta resultados falso-negativos. Valores semelhantes também foram encontrados por Médici, Alfieri \& Alfieri (2000) que estudaram 983 soros bovinos para avaliar um ELISA comercial para o diagnóstico do Herpesvírus Bovino tipo 1 (HBV-1) e encontraram 100\% de sensibilidade e $94,88 \%$ de especificidade. Santurio et al. (2006) também estudaram 116 soros de equinos para padronização de ELISA-i para pitiose e encontraram 97,72\% de sensibilidade e 90,27\% de especificidade. Semelhança com os valores obtidos neste estudo também foi verificado por Paredes et al. (1999) que ao analisaram 937 amostras de soro suíno para a padronização de um ELISA-i para peste suína clássica (PSC) e obtiveram 98,21\% de sensibilidade e 92,86\% de especificidade, definindo que o ELISA-i é um teste apropriado para o diagnóstico da PSC. Apesar dos valores preditivo positivo (VPP) e preditivo negativo (VPN) terem sido distintos, o elevado percentual do segundo assegura que animais que venham ser negativos no teste de ELISA-i, realmente não tenham a doença. Seguindo-se o que é preconizado pela OIE (2006) quanto à padronização e avaliação de testes diagnósticos, os valores de sensibilidade e especificidade de um ensaio são considerados ótimos quando superam os apresentados pelo gold test, como é o caso dessa pesquisa.

Mesmo havendo uma ótima concordância do ELISA-i quando comparado com o teste de fixação de complemento (FC) que possui sensibilidade em torno dos $90 \%$ a $95 \%$, este último tem o risco de apresentar reações falso-negativas ocasionalmente observadas no soro de alguns animais (jovens, gestantes ou idosos), além de reações falso-positivas que podem ocorrer em aproximadamente $1 \%$ dos soros testados ao se utilizar antígeno de células inteiras, o que o leva a ser superado pelos resultados obtidos no ELISA-i (Cravitz \& Miller 1950, Verma et al. 1990). 0 animal gestante que apresentou resultado positivo no ELISA e negativo na Fixação de Complemento, provavelmente deve-se à limitação desse último teste, que pode apresentar resultados falsos-negativos, especialmente em soros de burros, mulas e animais gestantes (Gregory \& Waag, 2008).

A diferença de DO observada nos resultados do ELISA-i frente aos soros dos cinco equinos submetidos à inoculação da bactéria inativada deve-se, provavelmente ao padrão de resposta inflamatória de cada animal. A intensidade dessa resposta irá depender do grau de infecção de cada equino (Amemiya et al. 2002).

A redução na quantidade de anticorpos, observada nos animais 60 dias após a inoculação com a B. mallei inativada provavelmente está relacionada ao período de soroconversão causado pelas proteínas desse agente que é de no máximo dois meses (Hagebock et al. 1993). Entretanto, exposições constantes de animais às proteínas do agente podem promover uma soroconversão permanente (Gregory \& Waag 2008).

As vantagens do desenvolvimento de um teste sorológico com antígeno nacional é o baixo custo de produção e, consequentemente, um provável aumento na aquisição do kit para diagnóstico o que poderá promover elevação do número de exames realizados, contribuindo com a redução dos casos da doença e até mesmo acelerar o processo de erradicação da doença no território nacional. Além disso, tendo em vista que espécies do gênero Burkholderia podem sofrer alterações em seu genótipo, principalmente quando se trata de cepas oriundas de regiões geográficas distintas (Silva et al. 2009), acredita-se que um kit nacional produzido a partir de cepas nacionais possa reduzir significativamente os índices de resultados falso-positivos observados atualmente na FC.

\section{CONCLUSÃO}

Com base nos resultados obtidos no ELISA-i, acredita-se que o teste é promissor para o diagnóstico sorológico do 
mormo em equídeos no Brasil. Sua versatilidade e praticidade, além do tempo empregado para realização o classificam como um teste que pode substituir a FC. Entretanto, ainda é necessária a realização de outros ensaios com maior número de amostras para realizar a etapa de padronização.

Agradecimentos.- Ao Conselho Nacional de Desenvolvimento Científico e Tecnológico - CNPq (processo no 578044/2008-0), à Fundação de Apoio à Pesquisa do Estado de Pernambuco (FACEPE, Proc. APQ-0772-5.05/06) pelo financiamento desta pesquisa e ao Ministério da Agricultura, Pecuária e Abastecimento (MAPA) pelo apoio.

\section{REFERÊNCIAS}

Al-Ani F.K., Al-Rawashdeh O.F., Ali A.H. \& Hassan F.K. 1998. Glanders in horses: clinical, biochemical and serological studies in Iraq. Vet. Archiv 68:155-162.

Amemiya K., Bush G.V., DeShazer D. \& Waag D.M. 2002. Nonviable Burkholderia mallei induces a mixed Tha and Th2 - like cytokine response in BALB/c mice. Infect. Immun. 70:2319-2325.

Brasil 2004. Instrução Normativa no 24 de 05 de abril de 2004, Ministério da Agricultura, Pecuária e Abastecimento, Brasília.

Burtnick M.N., Brett P.J. \& Woods D.E. 2002. Molecular and physical characterization of Burkholderia mallei 0 antigens. J. Bacteriol. 184(3):849852.

Cravitz L. \& Miller W.R. 1950. Immunologic studies with Malleomyces mallei and Malleomyces pseudomallei I: Serological relationships between M. mallei and M. pseudomallei. J. Infect. Dis. 86:46-51.

Dantas T.V.M. 2004. Desenvolvimento e padronização de ELISA indireto para diagnóstico de maedi-visna vírus em ovinos. Originalmente apresentada como dissertação de mestrado para o Programa de Pós-Graduação em Ciência Veterinária da Universidade Estadual do Ceará, Fortaleza.

Frey A., Di Canzio J. \& Zurakowski D. 1998. A statistically defined endpoint titer determination method for immunoassays. J; Immunol. Methods 221:35-41.

Gregory B.C. \& Waag D.M. 2008. Glanders, p.121-146. In Dembek Z.F. (Ed.), Medical Aspects of Biological Warfare. Office of the Surgeon General, United States Army, Falls Church, VA.

Hagebock J.M., Schlater L.K., Frerichs W.M. \& Olson D.P. 1993. Serologic responses to the mallein test for glanders in solipeds. J. Vet. Diag. Invest. 5:97-99.

Jana A.M., Gupta A.K., Pandya G., Verma R.D. \& Rao K.M. 1982. Rapid diagnosis of glanders in equines by counter-immuno-electrophoresis. Indian Vet. J. 59:5-9.

Leelayuwat C., Romphruk A., Lulitanond A., Trakulsomboon S. \& Thamlikitkul V. 2000. Genotype analysis of Burkholderia pseudomallei using randomly amplified polymorphic DNA (RAPD): Indicative of genetic differences amongst environmental and clinical isolates. Acta Tropica 77:229-237.

Madruga C.R., Araújo F.R. \& Soares C.O. 2001. Imunodiagnóstico em Medicina Veterinária. Embrapa Gado de Corte, Campo Grande, MS. 360p.

Médici K.C., Alfieri A.A. \& Alfieri A.F. 2000. Ensaio imunoenzimático comercial no diagnóstico sorológico das infecções por herpesvírus bovino 1. Ciência Rural 30(2):343-346.
Mota R.A., Brito M.F., Castro F.J.C. \& Massa M. 2000. Mormo em equídeos nos Estados de Pernambuco e Alagoas. Pesq. Vet. Bras. 20(4):155-159.

Mota R.A., Silva L.B.G., Silva K.P.C., Silva Neto J.B., Cunha A.P. \& Nascimento Sobrinho E.S. 2005. Caracterización bioquimica y perfil de sensibilidad antimicrobiana in vitro de muestras de Burkholderia mallei aisladas de équidos de la región nordeste de Brasil. Arqs Inst. Biológico, São Paulo, 72(1):7-11.

Mota R.A. 2006. Aspectos etiopatológicos, epidemiológicos e clínicos do mormo. Vet. Zootec. 13(2):117-124.

Naureen A., Saqib M., Muhammad G., Hussain M.H. \& Muhammad N. 2007. Comparative evaluation of Rose Bengal plate agglutination test, mallein test, and some conventional serological tests for diagnosis of equine glanders. J. Vet. Diagn. Invest. 19:362-367.

Neubauer H., Sprague L.D., Zacharia R., Tomaso H., Al Dahouk S., Wernery R., Wernery U. \& Scholz H.C. 2005. Serodiagnosis of Burkholderia mallei infections in horses: State-of-the-art and perspectives. J. Vet. Med. B, Infect. Dis. Vet. Public Health 52:201-205.

OIE 2006. Manual de Testes Diagnósticos e Vacinas para Animais Terrestres. Organização Internacional de Epizootias, Paris. Disponível em <http://www.oie.int> Acesso dez. 2011.

OIE 2008a. Glanders, p.823-838. In: Sánchez-Vizcaíno J.M. (Ed.), Manual of Diagnostic Tests and Vaccines for Terrestrial Animals. Organização Internacional de Epizootias, Madrid.

OIE 2008b. Manual of Diagnostic Tests and Vaccines for Terrestrial Animals: Principles of validation of diagnostic assays for infectious diseases. Organização Internacional de Epizootias, Paris. URL <http://www. oie.int/eng/normes/mmanual/2008/pdf/1.1.04 valid.pdf> p.34-45.

OIE 2010. World Animal Health Information Database Interface (WAHID). Organização Internacional de Epizootias. Disponível em <www.oie.int> Acessado em 6 jun. 2010.

Paredes J.C.M., Oliveira L.G., Braga A.C., Trevisol I.M. \& Roehe P.M. 1999. Development and standardization of an indirect ELISA for the serological diagnosis of classical swine fever. Pesq. Vet. Bras. 19(3/4):123127.

Santurio J.M., Leal A.T., Leal A.B.M., Alves S.H., Lübeck I., Griebler J. \& Copetti M.V. 2006. Teste de ELISA indireto para o diagnóstico sorológico da pitiose. Pesq. Vet. Bras. 26(1):47-50.

Silva K.P.C., Mota R.A., Cunha A.P., Silva L.B.G., Leal N.C., Cavalcanti Y.V.N., Teles J.A.A., Pereira M.C.C. \& Freitas N.S. 2009. Caracterização fenotípica e molecular de amostras de Burkholderia mallei isoladas na Região Nordeste do Brasil. Pesq. Vet. Bras. 29(5):439-444.

Silva K.P.C. 2010. Produção e avaliação da proteína derivada (PPD) de Burkholderia mallei para o diagnóstico imuno-alérgico do mormo em equídeos. Tese de Doutorado em Ciência Veterinária, Universidade Federal Rural de Pernambuco, Recife. 98p.

Tizard I.R. 2002. Imunologia Veterinária: uma introdução. 6aㅡ ed. Roca, São Paulo.

Verma R.D., Sharma J.K., Venkateswaran K.S. \& Batra H.V. 1990. Development of an avidin-biotin dot enzyme-linked immunosorbent assay and its comparison with other serological tests for diagnosis of glanders in equines. Vet. Microbiol. 2577-85. Elsevier Science Publishers, Amsterdam.

Verma R.D., Venkateswaran K.S., Sharma J.K. \& Agarwal G.S. 1994. Potency of partially purified malleo-proteins for mallein test in the diagnosis of glanders in equines. Vet. Microbiol. 41:391-397. 